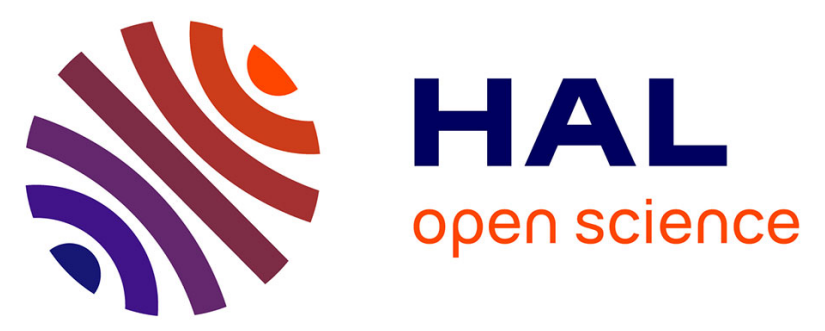

\title{
ABNORMAL MODULATION OF ELECTRODERMAL ACTIVITY BY THERMOALGESIC STIMULI IN PATIENTS WITH PRIMARY PALMAR HYPERHIDROSIS
}

\author{
Pedro Schestatsky, Marco A Callejas, Josep Valls-Solé
}

\section{To cite this version:}

Pedro Schestatsky, Marco A Callejas, Josep Valls-Solé. ABNORMAL MODULATION OF ELECTRODERMAL ACTIVITY BY THERMOALGESIC STIMULI IN PATIENTS WITH PRIMARY PALMAR HYPERHIDROSIS. Journal of Neurology, Neurosurgery and Psychiatry, 2010, 82 (1), pp.92. 10.1136/jnnp.2009.203687 . hal-00557445

\section{HAL Id: hal-00557445 \\ https://hal.science/hal-00557445}

Submitted on 19 Jan 2011

HAL is a multi-disciplinary open access archive for the deposit and dissemination of scientific research documents, whether they are published or not. The documents may come from teaching and research institutions in France or abroad, or from public or private research centers.
L'archive ouverte pluridisciplinaire HAL, est destinée au dépôt et à la diffusion de documents scientifiques de niveau recherche, publiés ou non, émanant des établissements d'enseignement et de recherche français ou étrangers, des laboratoires publics ou privés. 


\section{ABNORMAL MODULATION OF ELECTRODERMAL ACTIVITY BY THERMOALGESIC STIMULI IN PATIENTS WITH PRIMARY PALMAR HYPERHIDROSIS}

Pedro Schestatsky, MD, $\mathrm{PhD}^{1,2}$

Marco A. Callejas, $\mathrm{MD}^{3}$

Josep Valls-Solé, MD, $\mathrm{PhD}^{2^{*}}$

from

1. Neurology Service, Hospital de Clínicas de Porto Alegre, Brazil

2. Department of Neurology. Hospital Clínic. Universitat de Barcelona, Spain

3. Department of Surgery. Hospital Clínic, Barcelona, Spain

*Address for correspondence:

Josep Valls-Solé. MD, $\mathrm{PhD}$

EMG Unit. Neurology Department

Hospital Clínic. Villarroel, 170

Barcelona, 08036. Spain

Telephone: 34932275413

FAX: 34932275783

e.mail: jvalls@ clinic.ub.es

Total words in the manuscript: 2903

Key words: Primary palmar hyperhidrosis, Electrodermal activity, Thermoalgesic stimuli, Quantitative sensory testing. 


\section{ABSTRACT}

Background: We examined the effects of thermal stimulation on electrodermal activity (EDA) in patients with primary palmar hyperhidrosis (PPH). We hypothesized that temperature changes may induce abnormal sudomotor reactions because of simultaneous activation of sudomotor centers through thermal and emotional pathways. We compared patients before and after thoracoscopic sympathectomy.

Methods: We studied $18 \mathrm{PPH}$ patients and 20 controls. Patients reported subjective evaluation of their symptoms using a visual analogue scale for palmar sweating (ps-VAS) and for body sweating (bs-VAS). We applied focal thermal stimulation to quantify sensory perception and measure ongoing changes in EDA recorded from the palm of the hands.

Results: Before sympathectomy, patients had lower sensory perception thresholds and higher EDA levels than controls. Increased EDA occurred along the whole test, with no significant modulation by changes in thermal stimulation. Sensory perception normalized after sympathectomy but thermal modulation of EDA remained abnormal whenever sudomotor activity was present after surgery. There was a significant positive correlation between EDA levels before treatment and the bs-VAS (from $r=0.45$ to $r=0.57$ ).

Conclusions: Patients with PPH show perceptual abnormalities and exaggerated sudomotor reactions to thermoalgesic stimulation, consistent with central sensitization of sympathetic circuits. The reduced sympathetic outflow after thoracoscopic sympathectomy induced normalization of sensory perception but it did not modify the abnormal control of efferent sudomotor activity.

\footnotetext{
Abbreviations list (alphabetical order):

a-EDA = absolute electrodermal activity

bs-VAS = visual analogue scale for body sweating

EDA = electrodermal activity

$\mathbf{n}-\mathbf{E D A}=$ normalized electrodermal activity

PPH = primary palmar hyperhidrosis

ps-VAS = visual analogue scale for palmar sweating

VAS = visual analogue scale
} 


\section{INTRODUCTION}

Primary palmar hyperhidrosis (PPH) consists in excessive sweating of the hands with no identifiable cause.[1-4] Despite its prevalence and impact on quality of life, physiological mechanisms underlying PPH remain poorly understood.[4] The analysis of sudomotor skin response has shed some light on PPH pathophysiology by suggesting hyperexcitabilty of the somato-sympathetic circuits of PPH patients.[2,5,6] The sympathetic skin responses are usually examined with electrical stimuli, i.e., a non-natural stimulation. However, changes in electrodermal activity (EDA) can also be induced by thermal stimuli.[7] We were interested in knowing whether natural thermal stimulation was also capable of demonstrating abnormalities in the sudomotor circuits in PPH patients for three main reasons: First, thermal stimuli activate a well known subset of afferent fibres $[8,9]$ instead of the wide range of axons responding to electrical stimuli. Second, there is increasing evidence that brainstem autonomic centers, which contribute to the control of sudomotor activity, respond to thermoalgesic stimuli.[10-13] Third, thermal stimulation allows for on-line modulation of intensity, which helps to diminish the surprise effect of the sudden, phasic electrical stimulation, and permits recording the changes induced in EDA before, during and after stimulation.[7]

In the study reported here, we analyzed the changes in EDA induced by slow rising thermal stimulation of the skin at forearm level in patients with PPH before and after thoracoscopic sympathectomy. We further assessed thermal thresholds in the upper limbs of these patients to assess the possible correlation of these results with temperature-related C fiber function.

\section{METHODS}

The study was performed in 21 patients with PPH (10 women, 8 men, aged 25 to 45 years-old), recruited consecutively among those attending our clinic during the 6 months period January to June 2007. We also studied 20 healthy subjects, recruited among the spouses of the patients and colleagues to match for age and sex with those of the patients (10 women, 10 men, aged 24 to 46 years-old). No healthy subject or patient was under chronic medication regime or had any health condition known to affect the peripheral and autonomic nervous system functions or thermoalgesic perception. The evaluation was 
performed in a quiet, semidark room, at a temperature between $23.0{ }^{\circ} \mathrm{C}$ and $24.0{ }^{\circ} \mathrm{C}$. All subjects gave written informed consent for the study, which was designed in accordance to the Helsinki Declaration and approved by the Ethical Committee of the Hospital Clínic of Barcelona.

\section{Thoracoscopic sympathectomy}

After general anesthesia, a videothoracoscopic catheter was introduced through a trocar inserted in the axillary region. The second thoracic ganglion (T2) was identified, usually in the space between the second and third ribs. The sympathetic trunk was severed at this level, trying to isolate T2 and T3 ganglia, as performed in previous studies from our group.[2,6,17] The operation was carried out bilaterally, during the same surgical procedure.

\section{Clinical interview}

Interviews were carried out before and after thoracoscopic sympathectomy. PPH patients were asked how much the excessive sweating interfered with their routine activities of daily living by using a $10 \mathrm{~cm}$ visual analogue scale (VAS). The assessment was requested separately for the palms of the hands (palm sweating $=$ ps-VAS) and for the rest of the body (body sweating $=$ bs-VAS). The scales spanned from $0=$ no interference to 10 $=$ high interference with daily living. Clinical interview and tests were performed between 10 and 45 days before and 10 and 30 days after surgery. All studies were performed always at the same time of the day (early afternoon) by a single experimenter (PS), blinded for the clinical status of subjects.

\section{Thermoalgesic stimulation}

All temperature-related stimuli were applied with a Peltier type contact rectangular thermode from a Thermotest (Somedic, Sweden), with a stimulating area of $12.5 \mathrm{~cm}^{2}$. The thermode was attached with a velcro strip to the ventral aspect of the subject's mid forearm region. We first determined warm and heat pain thresholds using the method of limits. [14] This was considered the mean of three consecutive stimuli. Individual thresholds were used 
to determine the peak of the temperature stimuli to apply to that particular individual (see below).

\section{Experimental procedure}

Subjects were sitting on a comfortable chair. The Peltier thermode was attached to the distal ventral side of their forearm. We used thermal stimuli with ramp rates of $0.5^{\circ} \mathrm{C} / \mathrm{s}$ to a peak temperature intensity of $120 \%$ the individual's pain threshold. We performed 3 trials on each side, with an interval of at least 20 minutes between two consecutive trials. Subjects were asked to describe their subjective sensory perception using a $10 \mathrm{~cm}$ long linear analog potentiometer (RSA0N11S9002, Alps, Germany) installed in a metallic box and provided with a lever. We marked 7 labels on the side of the lever: "no temperature sensation"; "light warm"; "medium warm"; "high warm"; "light pain"; "medium pain" and "high pain". Subjects were instructed to be ready to move the lever with their right hand as soon as they felt any change in temperature, and keep marking the changes in the intensity of their sensations until the stimulation was over. The lever could be moved without resistance along its course, and the use of intermediate positions was encouraged. Signals from the lever (perception signals) were recorded together with the temperature signal generated by the Thermotest during the entire trial. They were digitized at a sampling frequency of $200 \mathrm{~Hz}$ and fed into a computer equipped with a software for off-line analysis (Acknowledge, Biopac Systems, Bionic Iberica, Spain).

\section{Electrodermal activity}

EDA was continuously monitored from 10 seconds before to 10 seconds after thermoalgesic stimulation through surface silver/silver chloride 9-mm-diameter recording electrodes attached to the skin of the palm (active) and dorsum (reference) of the subject's hands.[7,15,16] We assumed that there was a significant change in EDA when there was a negative or positive shift of the baseline level with an amplitude of at least $100 \mu \mathrm{V}$ and a duration of at least $0.5 \mathrm{~s}$. The signal was pre-amplified at a gain of $0.5 \mathrm{mV}$ using a NihonKhoden Neuropack-8 electromyograph (London). The output signal from the electromyograph was digitized with a band pass frequency filter set at $0.1-100 \mathrm{~Hz}$. 


\section{Data reduction and Statistical Analysis}

Onset of temperature change was considered time 0 (independent variable). In order to correlate sensory perception with EDA, we determined three time points in the sensory perception signal: (1) warm onset, as the time at which subjects marked their first perception of "light warm"; (2) pain onset, as the time when subjects marked perception of "light pain" and (3) peak of maximum sensation, as the time at which subjects reached their highest individual score. The highest individual score was defined as the percentage of the maximum possible lever displacement. This divided the sensory perception in 4 different segments (1) The "pre-perception phase", spanning from the beginning of recording (5 seconds before time 0) to warm onset; (2) the "warm phase", spanning from warm onset to pain onset; (3) the "pain phase", spanning from pain onset to the time in which subjects returned the tp-VAS lever to values lower than "light pain"; and (4) the "post-perception phase", spanning from the end of the "pain phase" until $5 \mathrm{~s}$ after the end of the stimulation. Temperature of the thermode was noted at each event. However, for the statistical analysis we only considered "light warm" and "light pain" latency values (warm and heat pain thresholds, respectively).

EDA was analyzed according to the sensory perception phases (Figure 1). Individual absolute EDA was calculated for each phase as the area under the curve, given in $\mu \mathrm{V}$ multiplied by phase duration (absolute EDA= a-EDA). In addition, because of the expected large interindividual differences in background EDA, statistical analyses were also done on normalized EDA (n-EDA), obtained by expressing the area of each phase as percentages of the individual's mean value calculated in the pre-perception phase for each condition.

Because none of our patients had asymmetrical sweating and no differences between sides were expected neither in sudomotor activity [15] nor in thermal thresholds,[18] data from both sides were pooled together. Normality of distribution of the data was assessed using Kolmogorov-Smirnoff. For descriptive statistics of quantitative data we report the mean and standard deviation values. The Student's t test and the chisquare test were used for comparison of demographic and clinical data between patients and controls. For comparisons between the three groups (controls, PPH before 
thoracoscopic sympathectomy and PPH after thoracoscopic sympathectomy) we used repeated-measures ANOVA. We also examined whether EDA values were different in each phase in the same individual, using one-way ANOVA, after pooling together data for all conditions. The Bonferroni's test was used for post-hoc analyses when significant differences were found. Finally, we examined the possible correlation between the amount of EDA in each sensory perception phase with the ps-VAS and bs-VAS using Pearson's correlation coefficient. A value of $\mathrm{p}<0.05$ was considered to indicate statistical significance.

\section{RESULTS}

Out of the initial 21 patients recruited for the study, three were lost during follow up after thoracoscopic sympathectomy for various reasons. Therefore, 18 patients were fully evaluated in both sessions. There were no differences between patients and control subjects with regard to sex (chi-square; $p>0.05$ ), age, weight and height (ANOVA; $>0.05$ for all comparisons). After sympathectomy, all patients reported a remarkable improvement of palm sweating with a reduction in the mean ps-VAS score from $9.4 \pm 0.7$ preoperatively to $2.9 \pm 2.0$ postoperatively (Student's t test; $\mathrm{p}<0.001$ ). In contrast, there was a significant increase in bs-VAS that patients attributed mainly to an increase in sweating in the head and trunk. Figure 2 shows the mean values for ps-VAS and bs-VAS before and after sympathectomy.

In control subjects, perception signals followed a quite stereotyped pattern, consisting on four well defined phases (Figure 3A): (1) After warm onset, perception increased more or less in parallel with the real temperature increase up to a mean temperature of $37.6 \pm 1.3{ }^{\circ} \mathrm{C}$; (2) Beyond this point, their perception remained mostly unchanged for a mean of $9.4 \pm 0.7 \mathrm{~s}$, giving rise to a relatively flat period; (3) Then, at a mean temperature of $42.3 \pm 1.8^{\circ} \mathrm{C}$, subjects marked a sudden increase up to the maximum pain score, followed by (4) a fast drop to baseline values, which was faster than the drop in temperature. There were noticeable differences in the sensory perception pattern of patients in comparison to control subjects (Figures 3B and 3C). Statistically significant differences were observed in the thresholds for warm sensation (ANOVA; $F[2,39]=25.6 ; p=0.03$ ), but not for heat pain sensation $(\mathrm{F}[2,39]=21.9 ; \mathrm{p}=0.6)$. Post-hoc analysis showed that differences were due to lower warm thresholds in patients with PPH before 
sympathectomy than in control subjects or in patients after sympathectomy (Bonferroni's test; $\mathrm{p}<0.001$ for all comparisons). There were no differences between patients after sympathectomy and controls (Bonferroni's test; $\mathrm{p}=0.2$ ). Table 1 displays thermal thresholds of all subjects groups. Differences were also observed in the mean slope of the relatively flat segment between warm and pain sensations. The mean slope between $38^{\circ} \mathrm{C}$ and $42^{\circ} \mathrm{C}$ was $0.02 \pm 0.005^{\circ} \mathrm{C} / \mathrm{s}$ in healthy subjects and $0.09 \pm 0.03^{\circ} \mathrm{C} / \mathrm{s}$ in patients before sympathectomy. This value showed a tendency to normalization after surgery, with a mean of $0.06 \pm 0.008^{\circ} \mathrm{C} / \mathrm{s}$.

Table 1. Psychophysical parameters measured in control subjects and patients with primary palmar hyperhidrosis (PPH) before and after thoracoscopic sympathectomy (TS).

\begin{tabular}{|c|c|c|c|c|}
\hline \multirow{2}{*}{$\begin{array}{c}\text { Thermoalgesic } \\
\text { Thresholds }\end{array}$} & Control subjects & \multicolumn{2}{|c|}{ PPH patients $(\mathrm{n}=18)$} & \multirow{2}{*}{$\mathrm{p}$} \\
\cline { 3 - 4 } & & Before TS & After TS & \\
\hline Warm $\left({ }^{\circ} \mathrm{C}\right)$ & $33.9(1.9)$ & $30.4(1.3)$ & $34.0(0.9)$ & 0.03 \\
\hline Heat pain $\left({ }^{\circ} \mathrm{C}\right)$ & $42.2(1.2)$ & $42.5(0.9)$ & $43.1(2.1)$ & NS \\
\hline
\end{tabular}

Table 1 legend. PPH, primary palmar hyperhidrosis; TS, thoracoscopic sympathectomy; NS, non-significant

Mean a-EDA was higher in patients than in control subjects in all phases (one-way ANOVA; $\mathrm{p}<0.01$ for all comparisons). In healthy subjects, EDA varied systematically according to the sensory perception phases. The statistical comparison between the 4 phases on n-EDA (normalized as percentage of the pre-stimulation phase) showed significant differences (ANOVA; $\mathrm{p}<0.05$ ), which were due to a higher $n$-EDA in the pain phase and lower n-EDA in the post-stimulation phase in comparison to the n-EDA in the pre-stimulation phase $(100 \%)$. In contrast, PPH patients before sympathectomy showed absence of phase-related changes in EDA. Figure 4 shows the mean and standard deviation values for n-EDA in all subjects groups for all sensory perception phases. A striking difference between patients and control subjects was the absence in patients of a marked 
decrease of EDA after the pain-sensation phase (Figures 3 and 4). Table 2 summarizes the mean and standard deviation values for a-EDA and n-EDA for each phase in control subjects and patients.

Table 2. Neurophysiological parameters of controls and patients with primary palmar hyperhidrosis (PPH) before and after thoracoscopic sympathectomy (TS).

\begin{tabular}{|c|c|c|c|c|c|c|c|}
\hline \multirow{2}{*}{ Phase } & \multicolumn{2}{|c|}{ Control Subjects } & \multicolumn{4}{|c|}{ PPH patients (n=18) } & \multirow{2}{*}{ p } \\
\cline { 4 - 7 } & \multicolumn{2}{|c|}{} & \multicolumn{2}{|c|}{ Before TS } & \multicolumn{2}{c|}{ After TS } & \multirow{2}{*}{ value } \\
\cline { 2 - 7 } & a-EDA & n-EDA & a-EDA & n-EDA & a-EDA & n-EDA & \\
\hline Pre & $11.7(5.0)$ & 100.00 & $33.7(8.2)$ & 100.00 & $19.9(11.3)$ & 100.00 & 0.001 \\
\hline Warm & $15.9(6.8)$ & $136.0(15.0)$ & $34.1(8.3)$ & $101.3(14.5)$ & $21.7(12.3)$ & $109.1(16.2)$ & 0.02 \\
\hline Pain & $19.6(8.4)$ & $168.3(13.2)$ & $34.4(8.4)$ & $101.9(12.2)$ & $24.9(14.1)$ & $124.9(14.1)$ & 0.01 \\
\hline Post & $7.3(3.1)$ & $62.8(8.9)$ & $33.1(8.1)$ & $98.2(8.8)$ & $8.6(4.9)$ & $43.1(7.5)$ & $<0.001$ \\
\hline
\end{tabular}

Table 2 legend. PPH, primary palmar hyperhidrosis; TS, thoracoscopic sympathectomy; aEDA, absolute EDA, given in $\mu \mathrm{V} / \mathrm{s}$; n-EDA, normalized EDA, given in percentage of the a-EDA mean value calculated in the pre-stimulation phase. NS, non-significant.

Finally, we found a positive correlation between the mean level of pre-treatment a-EDA and bs-VAS ( $r=0.45$ to $0.57 ; \mathrm{p}<0.01$ ), shown in Figure 5A. No significant correlation was found between ps-VAS before and bs-VAS ( $r=0.35$ to $0.48 ; \mathrm{p}=0.5)$ after sympathectomy.

\section{DISCUSSION}

The main findings of our study are: 1) Temperature-induced EDA is higher in patients with PPH than in controls, suggesting an abnormal effect of temperature inputs on autonomic centers; 2) Perception of warm sensation is altered in PPH patients, suggesting 
sensitization in the temperature perception pathway and; 3) There was a significant positive correlation between temperature-induced EDA and the magnitude of bs-VAS after treatment.

The finding of an increased activity in sudomotor pathways in patients with PPH is not new. Several authors have reported abnormalities of the sudomotor skin responses $[2,5,19]$ and skin conductance level,[6] other than those just related to the expected increase in the amount of sweating. Manca et al [2] applied pairs of electrical stimuli in the median nerve separated by increasing interstimulus intervals (ISI). The authors found that patients recovered the sudomotor excitability with lower ISIs in comparison with controls. In the same line, Lladó et al [6] observed higher prevalence of double peak sudomotor potentials in response to single electrical stimuli. Additionally, Chen et al [5] and Lefaucheur et al [19], found various abnormalities, including a higher occurrence of absent sudomotor responses, which were interpreted as indicative of "excessively busy" sweat glands. Such abnormalities persisted after thoracoscopic sympathectomy,[6] pointing out to an hyperexcitability of the somato-sympathetic circuits as a basic pathophysiological mechanism of PPH. As in previously published studies, we found that sudomotor activity was significantly reduced after sympathectomy. However, reflex sudomotor responses recorded with electrophysiological methods were still present in most of our patients. This could be due to unintended incompleteness of the sympathetic lesion. Thermal stimulation could have been a relatively strong one to cause activation of the remaining sympathetic circuits because of the coincidence of the stimulation activating both thermoregulatory and emotional sweating simultaneously.[16] Although the two forms of sweating might have different and independent control mechanisms and central drives,[16,20] thermal stimulation might have accessed the two circuits and induce a stronger output signal from sudomotor centers. A more efficient activation of the autonomic centers by thermal stimulation could explain why most responses were still present after sympathectomy, which is different from what has been reported with other types of stimulation.[5,19]

PPH patients had lower thresholds to warm stimuli compared to control subjects. This finding is in accordance with the observations reported by Schlereth et al.[21] who showed that acetylcholine sensitizes $\mathrm{C}$ afferent fibers and decrease thermal thresholds in normal subjects. In fact, there is convincing evidence that sympathetic postganglionic 
axons, which are hyperactive in PPH patients, excite primary afferent axons by activating alpha-adrenoceptors and generating activity in the "nociceptive pathway", which conveys warm and pain information up to the central nervous system.[22-24] A similar mechanism has been hypothesized to explain the analgesic effect of botulinum toxin,[25] in which case reduced acetylcholine liberation would decrease $\mathrm{C}$ fibers sensitivity. Our patients did not have clinical (i.e., pain or dysaesthesias) or neurophysiological signs (i.e., higher thermal thresholds) of small fiber disease, such as observed in diabetic patients with painful sensory neuropathy.[26] Therefore, our findings suggest that, apart from nerve injury, C afferent fibers can be sensitized by ongoing primary autonomic activity. For instance patients with complex regional pain syndrome type I are more sensitive than healthy subjects to temperature stimuli and sympathectomy has been proposed as an effective treatment for such patients.[27-29]

EDA reflects more than simply sweating activity. For example, sudomotor responses were present despite reduced skin sympathetic nerve activity and complete absence of sweating in an anhydrotic female carrier of Fabry's disease.[30] In addition, sympathectomy does not significantly affect the central nervous system abnormality underlying hyperexcitability of the somato-sympathetic sudomotor circuit at short term.[6] PPH patients might actually have a dysfunction in the autonomic centers of the brainstem that are both responsible for inhibition of sensory perception and peripheral autonomic activity. This hypothesis would explain lower thermal thresholds and higher autonomic responses of our PPH patients compared to normal subjects. It is also possible that the dysfunction resides at the cortical level, since the frontal or anterior cingulate cortex are prominently involved in the control of emotional sweating.[31] In the same line Fredrikson and cols.[32] observed that electrical stimulation at the thalamus, anterior cingulate and frontal cortex is able to modulate the sympathetic skin responses, and functional imaging studies have shown a positive correlation of sympathetic skin responses with neural activity in these areas in subjects experiencing emotional stimuli.[32] At subcortical level, the thalamus would be another candidate for mediating hyperhidrosis in certain conditions. Indeed, a misplaced electrode for deep brain stimulation was recently implicated in iatrogenic hyperhidrosis.[33] 
Our study has several limitations. First, one could argue that higher sudomotor activity and lower thresholds can also indicate a state of hypervigilance in patients with anxiety disorder. Although we did not assess anxiety symptoms, our patients were not under psychiatric treatment or in use of psychotropic drugs. Furthermore, no direct association between anxiety scores and hyperhidrosis was found in recent studies.[34,35] Second, we did not use objective tools for analyzing the nociceptive pathway such as nociceptive evoked potentials. However, the data on thermal thresholds were very reproducible within subjects. Third, we did not use sudomotor techniques that evaluate the peripheral autonomic pathway selectively and precisely i.e., QSART or silicone impressions.[16,36,37] Actually, changes in EDA reflect activity in a polysynaptic reflex circuit that includes central and peripheral components and the use of QSART could have allowed us to separate the effects of thoracic sympathectomy in both parts of the autonomic system.

We had a relatively small sample of patients. However, our findings were very consistent and reproducible. Thermal stimulation seems to provide meaningful results in the study of skin autonomic function in PPH patients. Our patients showed different and consistent phases of the ongoing sudomotor responses that could offer new possibilities for clinical and research purposes. For instance, the lack of EDA silent period observed in our patients was a new feature of PPH that has been detected by using slowly rising and falling thermal stimuli over the skin. Apart from that it seems that the temperature-induced EDA of PPH patients was a good predictor of compensatory sweating in short-term follow up after sympathectomy. More studies are justified in the future using combination of various natural stimuli and recording techniques to expand our knowledge on the pathophysiological mechanisms of PPH. 


\section{REFERENCES}

1. Moran KT, Brady MP. Surgical management of primary hyperhidrosis. Br J Surg. 1991;78:279-283.

2. Manca D, Valls-Solé J, Callejas MA. Excitability recovery curve of the sympathetic skin response in healthy volunteers and patients with palmar hyperhidrosis. Clin Neurophysiol. 2000;111:1767-1770

3. Atkins JL, Butler PE. Hyperhidrosis: a review of current management. Plast Reconstr Surg. 2002;110:222-228.

4. Eisenach JH, Atkinson JL, Fealey RD. Hyperhidrosis: evolving therapies for a wellestablished phenomenon. Mayo Clin Proc. 2005;80:657-666.

5. Chen HJ, Cheng MH, Lin TK, Chee EC. Recordings of pre- and postoperative sympathetic skin response in patients with palmar hyperhidrosis. Stereotact Funct Neurosurg. 1995;64:214-220.

6. Lladó A, León L, Valls-Solé J, Mena P, Callejas MA, Peri JM. Changes in the sympathetic skin response after thoracoscopic sympathectomy in patients with primary palmar hyperhidrosis. Clin Neurophysiol. 2005;116:1348-1354.

7. Schestatsky P, Valls-Solé J, Costa J, León L, Veciana M, Chaves ML. Skin autonomic reactivity to thermoalgesic stimuli. Clin Auton Res. 2007;17:349-355.

8. Hilz MJ, Azelrod FB, Schweibold G, Kolodny EH. Sympathetic skin response following thermal, electrical, acoustic, and inspiratory gasp stimulation in familial dysautonomia patients and healthy persons. Clin Auton Res. 1999;9:165-177.

9. Cervera A, Veciana M, Valls-Solé J. Sympathetic sudomotor skin responses induced by laser stimuli in normal human subjects. Neurosci Lett 2002;334:115-118.

10. Bingel U, Quante M, Knab R, Bromm B, Weiller C, Büchel C. Subcortical structures involved in pain processing: evidence from single-trial fMRI. Pain. 2002;99:313-321.

11. Rainville P, Bao QV, Chretien P. Pain-related emotions modulate experimental pain perception and autonomic responses. Pain 2005;118:306-318.

12. Zambreanu L, Wise RG, Brooks JC, Iannetti GD, Tracey I. A role for the brainstem in central sensitisation in humans. Evidence from functional magnetic resonance imaging. Pain. 2005;114:397-407. 
13. Veciana M, Valls-Solé J, Schestatsky P, Montero J, Casado V. Abnormal sudomotor skin responses to temperature and pain stimuli in syringomyelia. J Neurol. 2007;254:638645.

14. Fruhstorfer H, Lindblom U, Schmidt WC. Method for quantitative estimation of thermal thresholds in patients. J Neurol Neurosurg Psychiatry. 1976;39:1071-1075.

15. Claus D, Schondorf R. Sympathetic skin response. The International Federation of Clinical Neurophysiology. Electroencephalogr Clin Neurophysiol Suppl. 1999;52:277-282.

16. Vetrugno R, Liguori R, Cortelli P, Montagna P. Sympathetic skin response: basic mechanisms and clinical applications. Clin Auton Res. 2003;13:256-270.

17. Callejas Pérez MA, Grimalt R, Valls Solé J, Peri JM. Primary hyperhidrosis. Med Clin. 2002;119:659-665.

18. Yarnitsky D, Sprecher E, Zaslansky R, Hemli JA. Heat pain thresholds: normative data and repeatability. Pain. 1995;60:329-332.

19. Lefaucheur JP, Fitoussi M, Becquemin JP. Abolition of sympathetic skin responses following endoscopic thoracic sympathectomy. Muscle Nerve. 1996;19:581-6.

20. Bini G,Hagbarth KE,Hynninen P, Wallin BG. Regional similarities and differences in thermoregulatory vaso- and sudomotor tone. J Physiol 1980;306:553-565

21. Schlereth T, Brosda N, Birklein F. Spreading of sudomotor axon reflexes in human skin. Neurology. 2005;64:1417-21.

22. Levine JD, Taiwo YO, Collins SD, Tam JK. Noradrenaline hyperalgesia is mediated through interaction with sympathetic postganglionic neurone terminals rather than activation of primary afferent nociceptors. Nature. 1986;323:158-60.

23. Sato J, Perl ER. Adrenergic excitation of cutaneous pain receptors induced by peripheral nerve injury. Science. 1991;251:1608-10.

24. McLachlan EM, Jänig W, Devor M, Michaelis M. Peripheral nerve injury triggers noradrenergic sprouting within dorsal root ganglia. Nature. 1993;363:543-6.

25. Blersch W, Schulte-Mattler WJ, Przywara S, May A, Bigalke H, Wohlfarth K. Botulinum toxin A and the cutaneous nociception in humans: a prospective, double-blind, placebo-controlled, randomized study. J Neurol Sci. 2002;205:59-63.

26. Krämer HH, Rolke R, Bickel A, Birklein F. Thermal thresholds predict painfulness of diabetic neuropathies. Diabetes Care. 2004;27:2386-91 
27. Bosco Vieira Duarte J, Kux P, Duarte DF. Endoscopic thoracic sympathicotomy for the treatment of complex regional pain syndrome. Clin Auton Res. 2003;13:I58-62.

28. Singh B, Moodley J, Shaik AS, Robbs JV. Sympathectomy for complex regional pain syndrome. J Vasc Surg. 2003;37:508-11.

29. Baron R. Reflex sympathetic dystrophy and causalgia. Suppl Clin Neurophysiol. 2004;57:24-38.

30. Yamamoto K, Sobue G, Iwase S,Kumazawa K, Mitsuma T,Mano T.Possible mechanism of anhidrosis in symptomatic female carrier of Fabry's disease: an assessment by skin sympathetic nerve activity and sympathetic skin response. Clin Auton Res. 1996;6:107-110

31. Neafsey EJ. Prefrontal autonomic control in the rat: anatomical and electrophysiological observations. Prog Brain Res. 1990;85:147-166

32. Fredrikson M, Furmark T, Olsson MT, Fischer H, Andersson J, Langstrom B. Functional neuroanatomical correlates of electrodermal activity: a positron emission tomographic study. Psychophysiology. 1998;35:179-185

33. Diamond A, Kenney C, Almaguer M, Jankovic J. Hyperhidrosis due to deep brain stimulation in a patient with essential tremor. Case report. J Neurosurg. 2007;107:10361038.

34. Ruchinskas RA, Narayan RK, Meagher RJ, Furukawa S. The relationship of psychopathology and hyperhidrosis. Br J Dermatol. 2002;147:733-735.

35. Ramos R, Moya J, Turón V, Pérez J, Villalonga R, Morera R, Perna V, Ferrer G. Primary hyperhidrosis and anxiety: a prospective preoperative survey of 158 patients. Arch Bronconeumol. 2005;41:88-92.

36. Low VA, Sandroni P, Fealey RD, Low PA. Detection of small-fiber neuropathy by sudomotor testing. Muscle Nerve. 2006;34:57-61.

37. Illigens BM, Gibbons CH. Sweat testing to evaluate autonomic function. Clin Auton Res. 2009;19:79-87. 
Acknowledgments:

This work was done thanks in part to a grant from CAPES, Brazil, to PS, and a grant from FIS, Spain, to JVS (PI040970).

Licence for Publication:

The Corresponding Author has the right to grant on behalf of all authors and does grant on behalf of all authors, an exclusive licence on a worldwide basis to the BMJ Publishing Group Ltd to permit this article (if accepted) to be published in JNNP and any other BMJPGL products and sublicences such use and exploit all subsidiary rights, as set out in our licence.

Competing Interest: None declared. 


\section{FIGURE LEGENDS:}

Figure 1: Representative recording of a single control subject showing the temperature perception-based phases for the analysis of electrodermal activity (EDA). Recordings show the change in the actual temperature (temp), the signal indicating perception issued from the potentiometer (percept) and the electrodermal activity (EDA).

Figure 2: Self-perception of sweating in the palms (ps-VAS) and body (bs-VAS). The size of the bars represents the mean, and the length of the wisker represents standard deviation, obtained from patients with primary palmar hyperhidrosis before and after surgery. Note the significant decrease of ps-VAS and increase in bs-VAS after the procedure

Figure 3: Temperature stimulation (temp), sensory perception (percept) and electrodermal activity (EDA) recorded from a single representative subject from each group: control subjects (A), patients with primary palmar hyperhidrosis (PPH) before (B) and after sympathectomy (C). The tilted arrow in B points to the more pronounced slope of sensory perception in patients before surgery. The horizontal line and asterisk in control subjects point to the segment of quiet EDA after the peak of the stimulus. Note the absence of such segment in patients, a situation that did not change after sympathectomy.

Figure 4: Normalized elecrodermal activity (n-EDA) during the perception-based phases (pre-, warm, pain and post-perception phases). Note the lack of n-EDA variation in patients with primary palmar hyperhidrosis $(\mathrm{PPH})$, in comparison with controls, that is partially reversed after surgery 


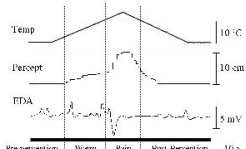

ligate 1 


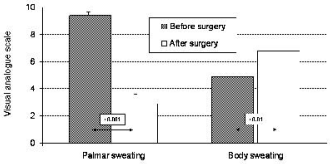

ligute 2 


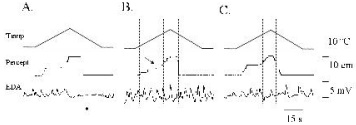

ligute : 


\section{Normalized Electrodermal activity}

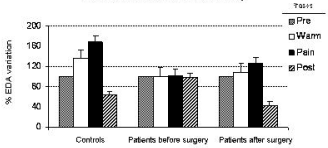

ligute 4 